\title{
Teachers' Voices: Pandemic Lessons for the Future of Education
}

\author{
Lesley G. Eblie Trudel \\ University of Winnipeg \\ Laura J. Sokal \\ University of Winnipeg \\ Jeff C. Babb \\ University of Winnipeg
}

\begin{abstract}
In late 2019 and early 2020, governments around the world closed educational institutions due to the COVID-19 pandemic. A similar response occurred in Canada and resulted in a sudden pivot by teachers from classroom-based instruction to remote teaching. During and shortly after this time, we undertook a survey study of over 2000 Canadian teachers, as well as follow-up interviews with a representative sub-set of those who took part in the initial round of the survey, to gain perspectives on teaching during the pandemic crisis. We summarize the foundations of the entire study and focus on the analysis and discussion of interview data to provide enhanced understanding of initial survey results. This study presents five lessons from the voices of teachers in the initial stages of COVID-19 in Canadian K-12 schools. Each lesson addresses a reality of teaching that was magnified by the pandemic and is highlighted for future consideration of educators in times of uncertainty and change.
\end{abstract}

\section{Introduction}

The COVID-19 pandemic has had an unprecedented effect on the lives of people around the world, and the result for Canadian society has been no different. Recently, imposed restrictions put in place to protect public safety and well-being have impacted federal and provincial legislation, as 
well as human rights. Restrictions on daily life have forced citizens to adapt the ways in which they work, learn and connect with one another (NESTA, 2020). According to the United Nations, Scientific and Cultural Organization (UNESCO, 2020), most governments world-wide temporarily closed educational institutions in response to the pandemic. Reflecting the international context, the impact on Canadian education has been wide-ranging and far-reaching. Decisions were made in spring 2020 to suspend classes in schools across Canada, with a sudden pivot to online, remote, or distance learning for students. The suspension of classes brought about a great deal of uncertainty and apprehension for educators, parents and community members (Eblie Trudel, 2021). With that in mind, we surveyed over 2000 Canadian teachers at three separate points during the year to gain their perspectives on a range of factors related to teaching during this pandemic crisis. Follow-up interviews were conducted with a representative sub-set of teachers after the initial round of the survey was completed. The interviews were done to gain greater insight into job demands as a result of the pandemic and resources available for support during this time, as well as perceptions about the future of teaching during a pandemic. This paper outlines the foundations of the entire mixed methods study, but specifically focuses on the analysis and discussion of the qualitative interview data. Anticipating a return to schools and classrooms as well as possible subsequent waves of COVID-19 which may require re-isolation, we documented the lived experiences of Canadian teachers, to ensure that the lessons learned are enduring and beneficial for teaching during times of uncertainty and change.

\section{Effects of Stress}

While teaching can be a stressful profession under typical circumstances (Johnson et al. 2005; Skaalvik \& Skaalvik, 2015; Van Veldhoven, 1996; Van Veldhoven \&Meijman, 1994), negative effects may result when teachers experience heightened stress levels over time. High stress can lead to lower quality teaching, poor health and well-being, and possible attrition from the profession (Bakker et al., 2014; Clunies-Ross et al., 2008; Harmsen et al., 2018; Maulana et al., 2015; Van Veldhoven \& Meijman, 1994). Additionally, high teacher stress has a negative effect on student achievement (Klusmann et al., 2016; Ronfeldt et al., 2013). On the other hand, while the job demands of teaching may cause stress, Jennings and Greenberg (2009) found that effective stress management leads to greater instructional competence. Kyriacou (2001) indicated that further research was required to assess the impact of internal resources (e.g. skills, attitudes, routines) and external resources (e.g. professional learning, technology, peer or administrator support) on teacher stress; this suggestion acquired additional significance during the current pandemic, given the additional demands placed on teachers beyond the regular classroom and school. We theorized that by identifying resources that teachers found helpful and ensuring that those resources were in place, teachers would be less impacted by stress and poor well-being, which has been shown to negatively affect student achievement (Arens \& Morin, 2016; Collie \& Martin, 2017; Klusmann et al., 2016). In other words, if teachers were well-supported, then students would also benefit.

\section{Theoretical Model of Stress}

An individual's ability to cope and flourish in an occupation is affected by specific factors associated with job stress. These factors are reflected in two categories: job demands and job resources. The Job Demands-Resources (JD-R) Model (Bakker \& Demerouti, 2007) considers 
both factors and is the theoretical model on which this research study is based. The model describes job demands as, "physical, psychological, social or organizational aspects of the job which require sustained physical and/or psychological (cognitive and emotional) effort or skills"; and job resources, as "physical, psychological, social or organizational aspects of the job that are either functional in achieving work goals, reducing job demands and the associated physiological and psychological costs in stimulating personal growth, learning and development" (Bakker \& Demerouti, 2007, p. 312). Bakker and Demerouti (2007) and McCarthy et al. (2015) defined stress as a mismatch between demands placed on a person and resources available to them. It is important to note that Gmelch (1983) differentiated between healthy stress which can promote growth and creative problem-solving in an individual, and high levels of unmanaged stress where the outcomes are negative for both the individual and the organization. Sustained periods of high stress can result in burnout. According to Maslach et al. (1996), burnout is a process characterized by three distinct stages: teachers first experience emotional exhaustion (perceiving too few resources to meet needs), then cynicism (towards students, parents or the community), followed by reduced selfefficacy (perception of limited competence in teaching). When resources are sufficient to meet job demands, stress is lowered and outcomes are positive. During a sustained period of high stress, this balance can be restored by decreasing demands or by increasing resources, with either predicted to have a variable effect on teachers as they move through the stages of burnout (Alarcon, 2011).

The JD-R model can not only demonstrate the role that resources play in buffering job demands, but it can also identify which resources are most effective in meeting particular job requirements. Additionally, the model recognizes that the balance between demands and resources may shift over time, resulting in individuals moving further toward or away from burn out (Bakker $\&$ Demerouti, 2007). The term 'resilience' in the social sciences has generally been defined as the ability to overcome negative life circumstances while gaining strength through the process (Henderson \& Milstein). In terms of the JD-R model, resilience describes the state of maintaining or regaining a positive balance of resources when compared to demands (Knight et al., 2010). Importantly, resilience does not mean that teachers do not perceive heightened job demands. Rather, it means that they make an appraisal of the demands and resources and determine that they have sufficient resources to meet the demands, a process reflected in the JD-R model (Bakker \&Demerouti, 2007). To summarize: a positive balance of resources to demands results in teachers demonstrating resilience; a negative balance of resources to demands elevates teacher stress and can, over time, lead to burn out. With this in mind, the research study set out to determine the changes in job demands for teachers resulting from the sudden pivot to remote learning and the impact of the possible resources available to support them during this time. The study also endeavored to gain insight into the perceptions of teachers regarding the future of teaching, specifically during periods of disruptive change such as the COVID-19 pandemic.

\section{Methods}

Our mixed methods (survey and interview) study was approved by the University of Winnipeg Human Research Ethics Board (UHREB) as meeting the standards of the TCPS-2. Both portions of the study were funded by an internal grant from the University of Winnipeg. The survey portion of the study is described here briefly, as respondents for the follow-up interviews were selected from the larger pool of survey participants. The survey itself was conducted between April $22^{\text {nd }}$ and May $14^{\text {th }}, 2020$, a time when students in Canadian schools had completed their spring break and teachers were engaging in remote, online and distance learning as a result of COVID-19. 
Teacher participants for the survey were recruited though snowball sampling. This method was chosen due to the time constraints imposed early in the pandemic. It was critical for the initial survey to be expedited to collect data when the pivot from classroom to remote learning first occurred. As a result, the initial link to the online survey was shared via email with professors at universities throughout Canada and also with practitioners in the field. Initial contacts in snowball sampling were encouraged to share the survey link with persons currently employed in the field of kindergarten to grade 12 teaching in Canada. When teachers clicked the link to the survey, they accessed a consent form and online survey located on Survey Monkey. The survey was anonymous and took approximately 15 minutes to complete. Once finished, participants were asked to generate a codename which would be used to link their data to subsequent survey data collection opportunities in June and September 2020.

\section{Participants}

Survey participants had the option to email the researchers to indicate their willingness to participate in a follow-up, thirty-to-sixty minute, non-anonymized telephone interview. Interview participants were required to sign written informed consent forms that explained the process and provided information concerning how data would be anonymized for publication purposes. Twelve follow-up interviews were conducted, with participants being provided with $\$ 25$ each as an honorarium at the end of the interview process. From the list of teachers who originally identified themselves as willing to participate in a qualitative interview process, participants were chosen through a method of purposeful sampling to include a broad representation of various characteristics in the group. All teachers interviewed were teaching during the spring of 2020. The characteristics for selection were recognized as follows: grades of students taughtearly/middle/senior; focus of instruction-generalist/specialist; language of instructionEnglish/French/Other; province of origin - represented according to survey results; and location of school-rural/urban. The twelve teachers who were interviewed had been in the profession between 1 and 37 years (median $=18.5$ years). The representation of teachers at various grade levels in the study was as follows: early years $(n=4)$, middle years $(n=5)$, early and middle years $(n=1)$; and senior years $(n=2)$. Six of the interview participants taught students core academic subjects (English Language Arts, Mathematics, Science, Social Studies and/or had general classroom assignments), while six participants taught students non-core subjects (Physical Education, Art or Music) or were engaged in roles such as alternative high school classroom or inclusion support. Nine of the participants taught in English programs and three in French Immersion. Participants' locations and settings were identified as follows: Manitoba $(n=6)$, New Brunswick ( $n=2)$, Alberta $(n=1)$, British Columbia $(n=1)$, and Nova Scotia $(n=2)$; Urban $(n=9)$, Rural ( $n=3)$; Public School $(n=10)$, and Private School $(n=2)$.

\section{Measures}

The interview questions had an initial section which requested general information regarding demographics and current teaching positions. This was followed by ten additional, openended questions regarding the participants' teaching experiences during the shift in instruction due to COVID-19. The questions were grouped into categories, with the first two questions pertaining to planning, delivery, and changes involved in instructional practice in order to sufficiently understand the context of teaching during a pandemic. These were followed by two questions regarding the job demands of teaching during the pandemic and ways to address stressful 
challenges. Next, there were four questions about internal and external resources that teachers found either helpful or unhelpful during remote teaching and learning. The interviews concluded with two questions pertaining to future directions suggested for administrators and recommendations for teaching in general, during a pandemic. For each participant, questions were asked verbally by our research team during a telephone interview. Two of the researchers on the team conducted six interviews each, which were audio-recorded and transcribed verbatim by separate research assistants. Periodically, as is common in qualitative research, there were probes and sub-questions asked by both the researchers, for purposes of clarification. These questions allowed the teachers interviewed to add greater detail to their responses, in order to ensure our understanding of the information that was provided.

\section{Data Analysis}

The responses of teacher participants in the study were analyzed by two of the researchers, using an inductive process within a Grounded Theory approach (Strauss, 1987; Corbin et al., 2015. In grounded theory, analyses support the creation of focused, conceptual theories which explain empirical phenomena. Charmaz (2006) elaborated on this practice, describing the coding and categorizing of data to create narratives throughout the process of analysis. Coding the data consisted of two main steps. First, the transcribed documents of all twelve interviews were read and substantively organized according to an emergent coding system. During the process of open coding, varied incidences in the data were noted, constantly compared and assigned codes. The researchers were careful to avoid redundancy and repetition and attempted to assign new codes to concepts where applicable. As a second step, a process of axial coding was applied. Through debate and discussion, individual interpretations of the data were compared, with the goal of developing a common understanding of the concepts and emerging relationships. Ambiguous statements were clarified, codes with similar interpretations were combined and in one instance a new code was introduced where elements of the data did not fit existing understandings. The researchers observed that the process of axial coding was similar to a having a lens to "magnify" the details from the data. In other words, the focus was placed on the participants' voices, the interactions between shared ideas, and the resulting relationships or linkages. A summary of the analysis of interview data is reported in Table 1.

Table 1.

Analysis of Interview Data.

\begin{tabular}{|l|l|}
\hline \multicolumn{1}{|c|}{ Open Coding Categories } & \multicolumn{1}{c|}{ Axial Coding Paradigms } \\
\hline 1.1 Missing the daily in-person rapport with students & 1. Caring Role of Teachers \\
1.2 Concern for student/family engagement & \\
1.3 Elevated worry about student well-being & 2. Inequities in Access to Learning \\
\hline 2.1 Inequitable means to connect with students & \\
2.2 Inadequate access to the Internet and digital devices \\
2.3 Challenges with language of instruction and inclusion
\end{tabular}




\begin{tabular}{|l|l|}
\hline $\begin{array}{l}\text { 3.1 Parental engagement during remote learning } \\
\text { 3.2 Responsive and supportive administration } \\
\text { 3.3 Teachers as respected and trusted professionals }\end{array}$ & $\begin{array}{l}\text { 3. Interdependence between } \\
\text { Parents, Teachers and } \\
\text { Administrators }\end{array}$ \\
\hline $\begin{array}{l}\text { 4.1 Perception of efficacy with new modes of teaching } \\
\text { 4.2 Balance between work and home life } \\
\text { 4.3 Importance of self-care and limit setting }\end{array}$ & 4. Importance of Self-Regulation \\
\hline $\begin{array}{l}\text { 5.1 Emphasis on inquiry-based, student centered approaches } \\
\text { 5.2 Focus on thematic, cross-curricular instruction } \\
\text { 5.3 Strengthening of professional learning communities }\end{array}$ & 5. Need for Engaging Instruction \\
\hline
\end{tabular}

Note: With regard to axial coding, samples of data from interview participants which align with the codes have been included in the findings to provide a more thorough understanding of teacher perceptions in each instance.

\section{Findings}

\section{The Caring Role of Teachers}

In reviewing the interview transcripts, it became apparent that the caring role of teachers was magnified during the period of remote instruction. Teachers described how much they missed seeing their students each day, observing their learning, supporting student challenges and celebrating their successes. Teachers had to adjust and find ways to engage and motivate learners when they were not together in the classroom. Teachers described how the shift to remote instruction elevated their concerns for students' well-being, particularly with students who had become disengaged from learning and with whom they had lost contact.

\subsection{Missing the daily in-person rapport with students.}

It's just so different. You're not next to your students when they're doing their work and you're not there for immediate feedback. The whole process of teaching and learning is really different online versus in-person.

\subsection{Concern for student/family engagement.}

What happens in the classroom is you're constantly assessing, observing and communicating. I don't have that. How I can communicate depends on the family situation and technology. Two-thirds of my class prefers paper copies. Most of them have access to technology; however, because of their age and multiple siblings, it's easier for the child to have paper in their hand so they can see it and so the family member can help them work through it while someone else is on the computer. I have a lot of students who are in multiple-child families. They're often the youngest, so they are low on the priority list of who gets to use the computer. If a family has three kids and they're all on different platforms, it gets to be too much. So, if I haven't heard from students, (when I contact them) I might get them to read for me, I might get them to talk me through their math strategies. 


\subsection{Elevated worry about student well-being.}

There are some (students) that I've been thinking about. Are they alright? Is everything okay at home? I'd normally check-in with them, but now it's a whole other process. A lot of our kids might not have the greatest home lives. They don't get the six hours away from their homes. It makes me quite worried. I know that they enjoy their instruction, but I think they enjoy all the aspects of school. Instruction is important, but they're missing out on everything else that's just equally as important to them.

\section{Lesson One - Prioritize Basic Needs Before Learning}

Doucet et al. (2020) asserted that the basic needs of children ought to be addressed prior to learning being embraced. Hence, they applied the phrase "Maslow before Bloom" (p.8), which aligned well with the perspectives obtained from teachers in this study. It was evident that caring teachers worried about their students beyond the central function of academic instruction. During the pandemic, teachers told us that regular contact with students allowed them to re-establish rapport, ensuring that students had adequate safety, food and support to meet their needs. Teachers found that by not having the opportunity to observe children and youth in their classrooms each day, concerns about student safety and security intensified. It became evident from concerns expressed in the interviews that the role of education extended beyond instruction and served the secondary purpose of monitoring and support for child health (mental health) and also safety.

\section{Inequities in Access to Learning}

Inequities observed by teachers during COVID-19 magnified and extended far beyond the challenges of the digital divide which had been reported previous to the pandemic (Bezuidenhout et al., 2017). During this period of remote delivery, it was necessary for learning materials to be provided to students in a variety of ways which extended beyond online supports. Many students did not have use of, or had restricted access to, technology (including the Internet, personal computers and cell phones). Children and youth who had access to the Internet and use of devices might not have been equitably supported if parents could not speak the language of instruction (French Immersion or English as an Additional Language), or if their children presented with special educational needs. Additionally, parents who were working or who had other childcare responsibilities might not have been able to support their children's learning in this new format.

\subsection{Inequitable means to connect with students.}

We did a survey of our homeroom classes, of who could learn online - parents that did not have that technology in the house, or device (cell phone, tablet etc.) would be signed up for an alternative delivery model. The Department of Education is sending out the one-size fits all program for two weeks that comes (in the mail) with the flyers.

\subsection{Inadequate access to the Internet and digital devices.}

If I could, I would make sure that everybody had everything they needed to have really effective online conversations. For example, if everyone had a device and headphones, with a microphone where I could hear them clearly and they could hear me - if their 
Internet wasn't cutting out; there are always tricky things with the microphones cutting out, somebody dropped the phone, or somebody's mom needed the phone, so they had to leave.

\subsection{Challenges in language of instruction and inclusion.}

There are a lot of other kids who are struggling with learning issues, emotional issues and this isn't a one size fits all kind of thing. Systems have to be put in place to support all kids.

\section{Lesson Two - Address the Systemic Inequities}

Teachers could see inequities in terms of access to learning that were beyond what had been reported previously. As remote learning responses to COVID-19 shifted to education online, the "digital divide" made it increasingly difficult for learners in marginalized populations to stay connected with instruction (Bezuidenhout et al., 2017). Additionally, the quality of Internet connection, access to devices (often shared by multiple family members with priority given to older youth or adults) and the ability for parents to connect with multiple technological platforms, made it complex and sometimes impossible for learning to occur. Bezuidenhout et al.,

(2017) further indicated that technology often replicates systemic inequalities which are apparent in our physical realities. COVID-19 exacerbated this phenomenon. Teachers reported that they and their administrators recognized the significant roles that they all played in addressing the inequities in the system which were being magnified during this time. Teachers and administrators worked to challenge these inequities through the provision of adapted and modified learning materials, and multiple ways to access learning, such as through online platforms, distance learning packages, phone calls, drive-by check-ins, and front yard visits.

\section{Interdependence between Parents, Teachers and Administrators}

The integral relationship between teachers, parents and administrators as partners in learning was magnified. Teachers and parents together create vital support systems which allow students to flourish under typical educational circumstances. During the COVID-19 pandemic, however, the systems were required to change. Students were now learning remotely under teacher direction, with parents supporting that learning at home. Teachers consistently expressed concern about whether leaders at the organizational level truly understood day-to-day demands in ways that would allow school districts to mitigate the challenges with effective resources and interventions. Trust was essential on the part of administration, as teachers continued in their roles remotely (with teachers often finding it challenging to learn multiple new digital platforms) while at the same time maintaining contact with students and instructing at a distance.

\subsection{Parental engagement during remote learning.}

We really work to build up that trust with families and a really good, positive, encouraging kind of rapport. I just feel like some of the directives are really proving overwhelming for a lot of families and this is breaking that trust a bit. They do not want to answer their phones and if we have to keep reaching out until we get hold of somebody, that's a lot of phone calls in a week. I just feel like it's harassment. 


\subsection{Responsive and supportive administration.}

Our school division (district) is just overwhelming us with the amount of resources they're finding, and I'm finding that not helpful. They're not focused on finding three or four that work. They're sending us out ten a day and it's (difficult) trying to keep up with it.

\subsection{Teachers as respected and trusted professionals.}

Trust that everyone is doing the best that they can. I think we're getting there, but that was one thing I think we struggled with at the beginning. I think it was that admin were struggling with the lack of control or knowledge of what we were doing outside of the building. It was a lot of emailing detailed reports and completing a lot of written essays about what we were doing. It felt like there was a suspicion that we were just sitting at home doing nothing when in fact it was the opposite and people were really struggling to learn all these new platforms and get in touch with families.

\section{Lesson Three - Strengthen the Context for Learning}

The relationship between teachers, parents and administrators with a collective focus on student learning was emphasized. Positive interdependence creates stability in systems (Johnson \& Johnson, 2009), and teachers noted the importance of key actions on the part of parents, administrators and themselves, which would strengthen the context for learning. Most critical was the effort not to overwhelm the system during this time. The message from teachers in this study was clear: Less is more. It was essential for administrators to avoid overloading teachers with resources and supports in early stages of teaching during the pandemic. When teachers initially focused on fewer and more familiar teaching mechanisms, they learned about new technological platforms and gained traction in their work. This over time allowed them to attempt more challenging instructional and technological approaches with students and families. Hence, balancing the appropriate level of supports and timing of resource provision with a subsequent reduction in demands, allowed for teacher resilience to be maintained (Knight et al, 2010) and burnout to be avoided (Alarcon, 2011). As noted in the JD-R model (Bakker \& Demerouti, 2007), when resources are sufficient to meet job demands, teacher stress is lowered and outcomes for students and families are favourable.

\section{The Importance of Self-Regulation}

Given the uncertainty, and unpredictability during the period of remote learning, the importance of self-regulation was magnified. Teachers struggled initially during the pandemic given the sudden pivot to remote learning. Teachers' efficacy and confidence were challenged with many expressing feelings of scrutiny from parents of their students and from school or district administrators. Teachers identified important internal resources that they activated in order to balance work and home life. Many shared that they were not only continuing to instruct their classes from home, but had their own children who required support for learning or had other demands in their personal lives. Teachers who set limits in terms of work time and space and practiced self-compassion reported success in coping and recovering efficacy during this period of remote learning. 


\subsection{Perception of efficacy with new modes of teaching.}

I also think about the quality of my teaching. Is this the expectation of the school of how I'm doing? I had some very involved parents throughout the school year. Since moving to this online model, I don't hear from them anymore. So, at first, I was wondering - am I doing a good enough job?

\subsection{Balance between work and home life.}

I think that because our administrator was also somebody who didn't have kids at home, they had forgotten what that might look like for some teachers. I think that we're getting there on the flexibility now, but that was something that was tough at the beginning. They were trying to say that people should work their normal days, but for some teachers with kids that's not possible because their children are awake during the normal work day some people are single parents, so if they need to send out the lesson plan at $5 \mathrm{pm}$, maybe that's all they can do.

\subsection{Importance of Self-Care and Limit Setting.}

I have to set more limits, because we always say that with teaching you're never done. There's always something else you can be doing. We're not used to what our boundaries should be right now because it's so brand new. It took me over twenty years to get good at boundaries in classroom teaching, and all of a sudden, I can't just transfer what I've learned. I can, but I have to do it again. I'm really trying to work at it.

\section{Lesson Four - Balance Demands and Resources}

Teachers identified the importance for self-regulation during this period of remote learning. They initially described feelings of uncertainty and exhaustion, similar to the initial stages of burnout noted by Maslach (1996), when teachers were faced with novel demands and noted unfamiliarity for how best to apply supports and resources within a new context Indeed, a perceived loss of efficacy by teachers in the early stages of the pandemic was indicative of a downshift described by Tschannan-Moran (1998) - a phenomenon that occurs when teachers are faced with strong external demands. Challenges of this nature decreased teachers' perceptions of efficacy, as did situations where teachers felt scrutiny from parents or administrators. Teachers reported, however, that this could be offset by positive collaboration (external resources) from colleagues. Teachers also suggested a number of strategies through the use of internal resources which helped them to more successfully balance the demands of both work and home. This included setting self-regulating boundaries in terms of work time and space, applying healthy eating, exercise and sleep habits, as well as, practicing self-compassion.

\section{Need for Engaging Instruction}

With the typical classroom context removed and a quick pivot to remote teaching and learning, the need for engaging instruction was magnified. Teachers told us that traditional 
instructional practices were insufficient to address curricular outcomes in the more abbreviated and sporadic time frames of remote learning. If curricular outcomes were going to be addressed effectively during this time, teachers told us that a focus on thematically approached, inquiry-based learning was a positive way to engage students. Teachers found it advantageous and reassuring to continue their work with colleagues and school teams, online, as they navigated the unprecedented crisis together. This approach was encouraged by administrators and functioned to strengthen existing professional learning communities with respect to team planning and collegial support.

\subsection{Emphasis on inquiry-based, student centered approaches.}

We have had some challenges from parents in understanding the provincial directives and how they apply to their child's learning. Some people are saying it's not enough and some people are saying it's too much. I think the big challenge is that parents of my students went to school when school looked a lot different than it does now. The idea that I teach thematically and in an integrated way throughout the year is less noticeable to them just because they're less involved day-to-day in their child's academics when we're in class. But as we've moved online, I think there are a lot of questions.

\subsection{Focus on thematic, cross-curricular instruction.}

I team teach with a great partner. Every week we have a theme. Just within my grade group, I know that if I reached out and needed help or ideas, or to run by things, they'll be quick to respond. That really helps because you're just thinking, how do I keep this fresh and engaging for kids for however many weeks?

\subsection{Strengthening of professional learning communities.}

I'm really relying heavily on my grade six team and the people I work with the most closely every day. It's just been really nice to stay connected. We have a group chat going throughout the day, or we'll have video calls after work and just chat about how things are going. So, it's nice to have the friendship connection there too. I think just trying to remain flexible and open to new ideas and ways of teaching have been important. The people around me have been the most helpful resources. Again, it's great having other ideas and a sounding board, and people who you know who are in the same situation as you.

\section{Lesson Five - Face the Challenges Together}

Teachers highlighted a need for more engaging instruction as a means to motivate students and sustain their attention and focus. Without consistent observation and monitoring of students in the venue of the school and traditional classroom, learning was essentially being redesigned by teachers in an effort to accommodate the new realities of remote instruction. Teachers reported a greater emphasis on inquiry-based, learner-centered approaches to engage students during this time. Teachers also indicated the use of thematic and cross-curricular learning in order to address student outcomes more consistently and authentically. Teachers worked with colleagues and school teams online as a continuation of the work begun within professional learning communities prior to the pandemic. This practice not only furthered the efforts to engage students, but strengthened existing collaborative processes in terms of instructional planning and support. In 
this regard, teachers perceived that they were no longer facing the challenges of remote learning alone, but that they were indeed 'all in this together.'

\section{Conclusions}

While teaching is acknowledged as a stressful profession under typical conditions (Johnson et al. 2005; Skaalvik \& Skaalvik, 2015; Van Veldhoven, 1996; Van Veldhoven \& Meijman, 1994), it was further impacted by the sudden pivot to online, remote or distance learning for students as a result of COVID-19. Given this context, it is understood that stress sustained over a period of time can lead to a state of occupational burnout (Gmelch, 1983). In education, high stress affects not only teacher health and welfare (Bakker et al., 2014; Clunies-Ross et al., 2008; Harmsen et al., 2018; Maulana et al., 2015; Van Veldhoven \& Meijman, 1994) but can have a negative effect on student achievement (Arens \& Morin, 2016; Collie \& Martin, 2017; Klusmann et al., 2016; Ronfeldt et al., 2013). Bakker \& Demerouti (2007) found, however, that an individual's ability to cope with stress in an occupation is largely affected by job demands and resources, and proposed a Job Demands-Resources (JD-R) model. Based on the JD-R model, our research team theorized that challenging job demands faced by teachers during this pandemic could be offset by helpful internal and external resources. Further, we believed that this would result in less chance of burnout and greater opportunities for coping and resiliency. Again, if teachers were supported, their students would also benefit. The five lessons presented here are evidence-based recommendations derived from the interview data. They helped us to understand more completely the demands involved with instructional practice during remote teaching and learning and to identify what teachers found helpful (and unhelpful) in terms of resources available to them. A summary of the lessons learned by teachers is reported in Table 2.

Table 2.

Pandemic Lessons for Educators.

\begin{tabular}{|l|l|l|}
\hline Lesson & \multicolumn{1}{|c|}{ Insights } & \multicolumn{1}{c|}{ Implications for Practice } \\
\hline 1 & Prioritize Basic Needs Before Learning & $\begin{array}{l}\text { Address basic needs, safety and } \\
\text { security of students, as a foundation } \\
\text { for teaching and learning. }\end{array}$ \\
\hline 2 & Address Systemic Inequities & $\begin{array}{l}\text { Challenge organizational } \\
\text { imbalances in multiple ways to } \\
\text { ensure that all learners can stay } \\
\text { connected with instruction. }\end{array}$ \\
\hline
\end{tabular}




\begin{tabular}{|l|l|l|}
\hline 3 & Strengthen the Context for Learning & $\begin{array}{l}\text { Reduce demands where possible } \\
\text { and provide the type and timing of } \\
\text { resources for teacher resilience to } \\
\text { be maintained - this will positively } \\
\text { impact students and families. }\end{array}$ \\
\hline 4 & Balance Demands and Resources & $\begin{array}{l}\text { Offset remaining demands and } \\
\text { challenges with key resources such } \\
\text { as the support of colleagues and } \\
\text { strategies such as self-regulation } \\
\text { and self-compassion. }\end{array}$ \\
\hline 5 & Face the Challenges Together & $\begin{array}{l}\text { Emphasize student-centered } \\
\text { instruction with the support of } \\
\text { professional learning communities } \\
\text { to maximize student engagement. }\end{array}$ \\
\hline
\end{tabular}

\section{Limitations}

Our interview data provided insights into the perspectives of Canadian teachers specifically relating to the job demands and resources they experienced during the early stages of the pandemic. These recommendations are proposed for educators by educators. While our findings carry with them limitations due to sample size and ability to generalize, the purposeful, in-depth interviews with this sub-set of teachers from our larger study provided richly textured information to supplement the phenomena under consideration.

\section{Implications}

As we settled into remote teaching and learning across Canada, and as schools gradually began to reopen in several provinces, it was a critical time to reflect on the final months of the 2019-20 school year. While this period of pandemic emergency response provided unprecedented challenges, it also presented opportunities to consider lessons learned by teachers and to use this evidence to navigate the future of education, especially during times of disruptive change. As Osmond-Johnson et al. (2020) avowed, questions needed to be answered as to the potential conditions necessary for students to learn, teachers to teach, and for educational leaders to adapt and support students. From the interview data analyzed in this study, our research team presented five practical lessons learned, as teachers began to navigate the early stages of COVID-19 in Canadian K-12 schools. The lessons couched in the categories identified by the researchers, magnified specific realities of teaching during a pandemic and provided the element of teacher voice that is essential for future consideration of educators in times of uncertainty and change. 


\section{Author Bio}

Dr. Lesley Eblie Trudel has been successfully involved in public education in Manitoba for over thirty years. She has held positions of classroom teacher, resource teacher, consultant, principal, and Assistant Superintendent of Schools. In January 2019, she joined the Faculty of Education at the University of Winnipeg. Currently Associate Dean in the faculty, Lesley is a collaborative leader and interdisciplinary researcher, with a keen interest in organizational learning and systemic change as it pertains to diverse, inclusive educational communities.

An award-winning teacher, Dr. Laura Sokal has published over 60 peer-reviewed research articles and 3 edited books on the psycho-social needs of today's students. Her SSHRC-funded research program includes studies ranging from adjustment in pre-school children to mental health issues in post-secondary students. Laura's extensive community service includes service on boards and committees concerned with social justice and creating meaningful and fair opportunities for vulnerable children, youth, and adults. Aside from working in schools in Canada and teaching in Australia, Turkey, Germany, and Nicaragua, Laura has served as the University of Winnipeg's Associate Dean of Education, and as a Child Life Therapist at Children's hospital. In her current role as Professor of Education at the University of Winnipeg, she enjoys learning with and from her students.

Jeff Babb is an Associate Professor with the Department of Mathematics and Statistics at the University of Winnipeg. He joined the Department in September of 2000 and served as its Chair from 2004-2009. Jeff was a Principal Consultant for the Statistical Advisory Service in the Department of Statistics at the University of Manitoba from 1998-2000. Previously he served as the Biometrician for the Grain Research Laboratory of the Canadian Grain Commission in Winnipeg for 16 years, and earlier as a Research Officer with Alberta Hospitals and Medical Care in Edmonton. Jeff has extensive statistical consulting experience with industry, government and academia in the planning, design, implementation, analysis and reporting of scientific research projects and in the design and analysis of questionnaires and surveys. Currently, Jeff's research interests include multivariate analysis, spatial statistics, simulation, climatology, demography, and history of mathematics.

\section{References}

Alarcon, G. (2011). A meta-analysis of burnout with job demands, resources, and attitudes. Journal of Vocational Behavior, 79(2), 549-562.

Arens, A., \& Morin, A. (2016). Relations between teachers' emotional exhaustion and students' educational outcomes. Journal of Educational Psychology, 108(6), 800-813.

Bakker, A., \& Demerouti, E. (2007). The job demands-resources model: State of the art. Journal of Managerial Psychology, 22, 309-328. 
Bakker, A., Demerouti, E., \& Sanz-Vergel, A. (2014). Burnout and work engagement: The JD-R approach. Annual Review of Organizational Psychology, 1, 389-411.

Bezuidenhout, L., Leonelli, S., Kelly, A., Rappert, B. (2017). Beyond the digital divide: Towards a situated approach to open data. Science and Public Policy, 44(4) 464-475.

Charmaz, K. (2006). Constructing grounded theory: A practical guide through qualitative analysis. Sage Publications Inc.

Clunies-Ross, P., Little, E., \& Kienhuis, M. (2008). Self-reported and actual use of proactive and reactive classroom management strategies and their relationship with teacher stress and student behaviour. Educational Psychology, 28(6), 693-710.

Collie, R., \& Martin, A. (2017). Teachers' sense of adaptability: examining links with perceived autonomy support, teachers' psychological functioning, and students' numeracy achievement. Learning and Individual Differences, 55, 29-39.

Corbin, J. \& Strauss, A. (2015). Basics of qualitative research: Techniques and procedures for developing grounded theory. Sage Publications Inc.

Doucet, A., Netolicky, D., Timmers, K., \& Tuscano F. (2020). Thinking about pedagogy in an unfolding pandemic: An independent report on approaches to distance learning during COVID19 school closures. Education International and UNESCO Version 2.0. https://issuu.com/educationinternational/docs/2020_research_covid-19_eng

Eblie Trudel, L. (2021). Remote learning for students with additional needs. [PowerPoint presentation]. https://www.ncfu.ru/science/scientific-events/

Cifrovaya-transformaciya-inkluzivnogo-obrazovaniya-v-usloviyah-pandemii-COVID-19/

Gmelch, W. (1983). Stress for success: How to optimize your performance. Theory into Practice, 22(1), 7-14.

Harmsen, R., Helms-Lorenz, M., Maulana, R., \& van Veen, K. (2018). The relationship between beginning teachers' stress causes, stress responses, teaching behaviour and attrition. Teachers and Teaching, 24(6), 626-643.

Jennings, P., \& Greenberg, M. (2009). The prosocial classroom: Teacher social and emotional competence in relation to student and classroom outcomes. Review of Educational Research, 79, 491-525.

Johnson, S., Cooper, C., Cartwright, S., Donald, I., Taylor, P., \& Millet, C. (2005). The experience of work-related stress across occupations. Journal of Managerial Psychology, 20(2), 178187.

Johnson, D., \& Johnson, R. (2009). An educational psychology success story: Social interdependence theory and cooperative learning. Educational Researcher, 38, 365-379.

Klusmann, U., Richter, D., \& Lüdtke, O. (2016). Teachers' emotional exhaustion is negatively related to students' achievement: Evidence from a large-scale assessment study. Journal of Educational Psychology, 108, 1193-1203.

Knight, C., Balatti, J., Haase, M., \& Henderson, L. (2010, July 4-7). Preservice teacher stressors and their reactions to those stressors: resilient responses [Conference proceedings]. Australian Teacher Education Association Conference, Townsville, QLD, Australia.

Kyriacou, C. (2001). Teacher stress: Directions for future research. Educational Review, 53(1), $27-35$.

Maslach, C., Jackson, S., \& Schwab, R. (1996). Maslach Burnout Inventory - educators survey (mbi-es). In C. Maslach, S.E. Jackson, \& M.P. Leiter (Eds.), MBI Study (3d ed., pp. 191-218). Consulting Psychologists Press. 
Maulana, R., Helms-Lorenz, M., \& van de Grift, W. (2015). Development and evaluation of a questionnaire measuring pre-service teachers teaching behaviour: A Rasch modelling approach. School Effectiveness and School Improvement, 26, 169-194.

McCarthy, C., Lambert, R., Lineback, S., Fitchett, P., \& Baddouh, P. (2015). Assessing teacher appraisals and stress in the classroom: Review of the classroom appraisal of resources and demands. Educational Psychology Review, 28, 577-603.

National Endowment for Science Technology and the Arts - NESTA (2020). Unprecedented times: Taking action during COVID-19. https://www.nesta.org.uk/feature/ unprecedented-times/

Osmond-Johnson, P., Campbell, C., \& Pollock, K. (2020). COVID-19 era: Reflections for Canadian education. EdCan Network. https://www.edcan.ca/articles/ moving-forward-in-the-covid-19-era/

Ronfeldt, M., Loeb, S., \& Wyckoff, J. (2013). How teacher turnover harms student achievement. American Educational Research Journal, 50, 4-36.

Skaalvik, E., \& Skaalvik, S. (2015). Job satisfaction, stress and coping strategies in the teaching profession - What do teachers say? International Education Studies, 8, 181-192.

Strauss, A. (1987). Qualitative analysis for social scientists. Cambridge University Press.

Tschannen-Moran, M., \& Hoy, A. (2001). Teacher efficacy: Capturing an elusive construct. Teaching and Teacher Education, 17(7), 783-805.

Vakola, M., \& Nikolaou, I. (2005). Attitudes toward organizational change: What is the role of employees, stress and commitment? Employee Relations, 27(2), 160-174.

Van Veldhoven, M. (1996). Psychosociale arbeidsbelasting en werkstress (Psychosocial job demands and work stress). [Unpublished doctoral dissertation]. University of Groningen, The Netherlands.

Van Veldhoven, M., \& Meijman, T. (1994). Het meten van psychosociale arbeidsbelasting met een vragenlijst: De Vragenlijst Beleving en Beoordeling van de Arbeid (VBBA) [The measurement of psychosocial strain at work: the questionnaire experience and evaluation of work]. NIA.

United Nations Educational, Scientific and Cultural Organization - UNESCO (2020). COVID-19 educational disruption and response. https://en.unesco.org/covid19/educationresponse

ЛL 